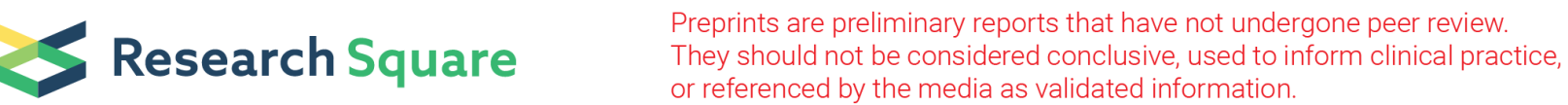

\section{The One Who Doesn't Take ART Medication Has no Wealth at All and No Purpose on Earth - a Qualitative Assessment of How HIV-Positive Adults in Uganda Understand the Health and Wealth- Related Benefits of ART}

Uzaib Saya ( $\nabla$ uzaibsaya@gmail.com )

Pardee RAND Graduate School

\section{Sarah MacCarthy}

University of Alabama at Birmingham School of Public Health

\section{Barbara Mukasa}

Mildmay Uganda, Mildmay Hospital and Institute of Health Sciences

\section{Peter Wabukala}

Mildmay Uganda, Mildmay Hospital and Institute of Health Sciences

\section{Lillian Lunkuse}

Mildmay Uganda, Mildmay Hospital and Institute of Health Sciences

\section{Zachary Wagner}

RAND Corporation

\section{Sebastian Linnemayr}

RAND Corporation

\section{Research Article}

Keywords: HIV/AIDS, antiretroviral therapy (ART), Uganda, adherence, qualitative analysis

Posted Date: February 3rd, 2022

DOI: https://doi.org/10.21203/rs.3.rs-1280787/v1

License: (c) (1) This work is licensed under a Creative Commons Attribution 4.0 International License.

Read Full License 


\section{Abstract \\ Background}

Increases in life expectancy from antiretroviral therapy (ART) may influence future health and wealth among people living with HIV (PLWH). What remains unknown is how ART clients perceive the benefits of ART adherence, particularly in terms of improving health and wealth in the short and long-term at the individual, household, and structural levels. Understanding these future-oriented attitudes towards ART can help to promote ART expansion among donors and other policymakers while also providing insights into the broader benefits of ART for PLWH.

\section{Methods}

In this qualitative study, we conducted semi-structured interviews among a subsample of 40 clinicenrolled ART clients participating in a randomized clinical trial for treatment adherence in Uganda (clinicaltrials.gov: NCT03494777). Interviews were transcribed verbatim and translated from Luganda into English. Two co-authors independently reviewed all transcripts, developed a detailed codebook, achieved $93 \%$ agreement on double-coded interviews, and analyzed data using inductive and deductive content analysis. Applying the social-ecological framework at the individual, household, and structural levels, we examined how PLWH perceived benefits of ART as they relate to health and wealth.

\section{Results}

Our findings revealed several benefits of ART expressed by PLWH, going beyond the short-term health benefits to also include long-term economic benefits related to taking their medication. Such benefits largely focused on the ability of PLWH to live longer and be physically and mentally healthy, while also fulfilling responsibilities pertaining to themselves (especially in terms of positive long-term habits and motivation to work harder), others (such as improved relations with family and friends), and society (in terms of reduced stigma, increased comfort in disclosure, and higher levels of civic responsibility).

\section{Conclusions}

Interventions and programming designed to shape ART uptake should explore emphasizing the broader benefits of ART at the individual, household, and structural levels. Having such benefits directly integrated into the design of clinic-based HIV interventions through targeted messaging towards certain groups of people (e.g., women seeking to start a family) can be useful especially for PLWH who face competing interests to increase medication adherence. These benefits can ultimately help providers and policymakers better understand PLWH's decision-making as it relates to improving ART-related outcomes. 


\section{Introduction}

Globally, almost 25.4 million people are now accessing lifesaving antiretroviral therapy (ART) [1]. Increased access to ART has been shown to improve the health, quality of life, and life expectancy of people living with HIV (PLWH) [2-4]. However, maximizing the benefits from ART-such as delayed HIVrelated symptoms-depends on optimal retention in care and continued adherence to treatment over time (also called ART persistence). Poor adherence, such as missing doses, could increase a person's viral load and the risk for transmitting HIV. In Uganda, less than half of PLWH achieve $85 \%$ adherence to their ART medication [5]. Sustained engagement in HIV care and adherence to ART is largely determined by longterm individual behavior, as well as issues at the household and structural levels (especially those influenced by economic, institutional, political factors) [6-10].

Evidence from the HIV and public health literatures indicate that there are various demand and supplyrelated reasons for ART initiation and continued adherence-these include socio-demographic and socioeconomic characteristics, existing health status, affective factors (such as fear of stigma, depression), social support, as well as institutional and health system barriers [11]. While these factors help understand how ART adherence is shaped, it is equally important to understand how long-term factors can be leveraged to promote ART investment and sustain present-day ART adherence. One way to do this is to consider how such treatment provides benefits in the future. Evidence from the economics literature shows that declining mortality and increased life expectancy shape future-oriented behavior and affect economic choices and human capital investments $[12,13]$. The availability of an HIV treatment that increases life expectancy by an average of 18 years [14] could potentially alter how individuals consider health-related risk-taking and information-seeking, and wealth-related investment decisions. Highlighting the perceived benefits of ART adherence in the short and long-term, especially how it affects both health and wealth can be a promising approach to expand ART use. Prior quantitative literature from the HIV context has examined how information about testing and ART availability changes subsequent behavior. Studies from Kenya and Tanzania suggest that individuals who expected an HIV positive result but tested negative were more likely to change behaviors that increased their risk for contracting HIV, indicating that HIV test results influence behavior when providing unexpected information [15]. When ART was made available in Kenya, female PLWH reported a $70 \%$ increase in pregnancies and $35 \%$ increase in selfreported sexual behavior [16]. These estimates suggest that availability of HIV testing and treatment can change health behaviors, but exactly how and why individuals change their behaviors is not well understood. A study from Malawi found that improved ART availability decreased individuals' selfreported mortality risk as measured by their life expectancy, but also increased labor supply, and futureoriented expenses in their children in the form of their education and clothing expenses $[17,18]$. There is also some evidence from South Africa suggesting that increased knowledge about ART-related life expectancy gains had an effect on human capital investments [19]. Understanding how individuals perceive benefits of ART use on other domains such as wealth can help promote expansion of, and investment in ART. 
In this qualitative study, we explored the perceived benefits of ART adherence on health and wealth at the individual, household, and structural levels. We interviewed adult PLWH at an HIV clinic in Kampala, Uganda where the waiting area had visible reminders and cues about the positive influence of ART (Appendix B)-these cues initially served as motivation for exploring our research question more rigorously using one-on-one interviews with ART clients. The results from this study can guide policymakers and researchers alike in understanding sustained ART use and how ART affects the broader lives of PLWH.

\section{Methods}

Our qualitative study reported is informed by the Consolidated Criteria for Reporting Qualitative research (COREQ) [20] (Appendix A).

\section{Study Sample}

Between July-August 2018, we conducted semi-structured interviews with a purposive sample of 40 HIVpositive adults who were enrolled in a randomized controlled trial (RCT) called "Behavioral Economics Incentives to Support HIV Treatment Adherence" (BEST) (clinicaltrials.gov: NCT03494777) [21]. This twoyear trial is testing the efficacy of using small lottery incentives to support ART adherence for treatmentmature HIV clients.

The participants were all patients at Mildmay Uganda, a clinic in Kampala, Uganda that specializes in the provision of comprehensive HIV/AIDS prevention, care, and treatment services. They were recruited into the RCT and were all 18 years of age or older, receiving ART at the participating clinic for 2 or more years, and had demonstrated recent adherence problems within six months of being recruited based on clinical records (defined as showing lack of viral suppression, being sent to adherence counseling, or at disease stage 3 or 4 as per WHO guidelines). Individuals were excluded if they were not able to provide informed consent, spoke neither English nor Luganda (the local language), were participating in any other adherence-related study, were inconsistently using the trial-issued Medication Event Monitoring System (MEMS) cap to monitor adherence, used third-line treatment, or came to the clinic outside regular working hours.

\section{Recruitment}

We used Mildmay's electronic medical record system to identify eligible participants. Once identified in the clinic database, the study team took note of the subsequent recruitment opportunity based on their next available date of appointment. The study coordinators then looked out for individuals due for a visit that day and approached all eligible participants in-person and inquired whether s/he was interested in participating in an ongoing study. Respondents were assured they would not lose their spot in the queue for any clinic services. Those individuals that initially agreed were taken to a separate study room to verify eligibility, and the survey objective and procedures were explained. Once the participant gave written informed consent to participate in the RCT, s/he was given a MEMS cap to monitor real-time 
adherence and instructed to store their HIV medication in a pill bottle with the MEMS-cap attached. The qualitative interview was then conducted with only the participant and interviewer present in the room, and the participant was compensated USh 20,000 (equivalent to US \$5) for participation. The target sample size was 40 ART clients as this was expected to be sufficient to achieve saturation.

\section{Data Collection}

A team of one male and one female trained qualitative researchers (co-authors LL and PW) conducted semi-structured interviews in English and/or the local language Luganda at the preference of the participant, with interviews typically lasting 30-40 minutes. The interviewers (one male, one female) had undergone an extensive 30-hour qualitative interview training (led by co-authors UYS and SM) and had previously conducted other qualitative and quantitative studies with PLWH, especially those with ART adherence challenges. The interview guide (Appendix C) focused on understanding the determinants of ART adherence, as well as the effects of ART adherence on health, life expectancy, and wealth. Prior to interviews with any study participants, the data collection team piloted the interview guide among themselves and other team members to ensure use of appropriate language and local context cues. Open-ended questions focused on the key facilitators and challenges in taking ART, how ART affected health currently and in the future, and whether taking ART as prescribed would also influence wealth and life expectancy.

All interviews were audio-recorded, transcribed verbatim and translated from Luganda into English, and stored on a secure data portal. Repeat interviews were not carried out. To ensure confidentiality, we separated personal identification information from the response data, and respondents were only identified through their clinic ID. Approximately $20 \%$ of the participant interviews were re-transcribed by an additional team member for quality control and re-evaluated against the original transcript to ensure consistency. The transcripts were then entered into Dedoose software. Transcripts were not returned to participants for comment and/or correction.

The interview team met regularly with two co-authors (UYS and SM) over the course of three weeks to discuss feedback on how participants described the effects of ART adherence on health and wealth. The team also discussed any problems that came up relating to interviewing goals and techniques. Troubleshooting involved improving the style of interviewer probing especially when they encountered issues such as when respondents said there was nothing stopping them from taking medications and did not report any barriers to taking ART. Interviewers were instructed to probe further on these points since all participants were eligible for the parent RCT because of adherence-related problems. Another issue raised was that of translating certain words into the local language, Luganda - for example, the words "health" and "lifestyle" are often interchangeable. As a result, when asked about the effects of ART on one's health, many respondents provided responses focused on their life goals (e.g., job, home, family etc.) rather than discussing immediate health-related impacts.

Demographic and adherence data on 38 of the 40 enrolled clients were obtained from a follow-up baseline interview in October 2018-January 2019. In 2 cases (5\% of overall sample), data were not 
obtained due to non-participation in the follow-up baseline interview. At this stage, the participants had either dropped out of the study, or the MEMS-recorded adherence was less than $30 \%$, which made them ineligible to continue in the parent study. Participants were typically eligible for their baseline interview three months after the pre-baseline visit when the qualitative interviews were conducted. These quantitative data included age, sex, level of education, marital status, WHO HIV infection stage, employment status, MEMS-measured adherence, and whether participant currently had undetectable viral load (to act as a proxy for the biological response to ART). These data were used as participant descriptors and if relevant, to gauge qualitative differences across groups of participants (e.g., by sex, infection stage etc.).

\section{Theoretical Framework}

To thematically categorize data in terms of participants' attitudes and expectations of future outcomes from ART adherence, we relied on health behavior change frameworks that incorporated behavioral learning theory, such as the theory of planned behavior which examines individual beliefs, perceptions, and ease of behavior change $[22,23]$. In the case of our study sample, we sought to understand how PLWH perceived the benefits of ART adherence in the short and long-term, especially how factors at the social ecological levels shaped how they evaluated their own pill-taking behavior [24]. The socialecological model has been extensively studied and used to understand how factors with various domains determine health behavior such as ART adherence $[25,26]$.

In this study, we hoped to better understand the extent to which factors at the individual, household, and structural levels influenced how PLWH perceived the benefits of ART. The individual level identified intrapersonal influences including the experiences and attitudes towards the long-term impacts of ART adherence, while the household level examined interpersonal factors incorporating social dynamics with family and friends, while the structural factors included the larger political and cultural context and includes beliefs such as stigma and fatalism, and beliefs about disclosure to family and friends that may influence individuals' ability to assess the effects of ART on health and wealth.

\section{Analysis}

We used a combination of inductive and deductive content analysis to categorize data based on emergent themes as well as previously structured hypotheses $[27,28]$. We repeatedly read the 40 transcripts to become familiar with the data managed in Dedoose, and coded the data based on recurring key issues and themes. We developed a structured coding framework based on a close assessment of all transcripts that included themes as well as content descriptions, inclusion/exclusion criteria, and sample quotes. Additional codes were created based on reading the transcripts. The coders double-coded eight interviews separately to reach a total of 130 excerpts, after which 30 were randomly picked using a random number generator, and each coder blind-coded them. This resulted in $93 \%$ agreement, after which one coder (UYS) continued coding the remaining interviews. These coders met biweekly thereafter to identify any emerging themes and discuss any questions or concerns. Once all coding was completed, one coder (UYS) read the excerpts per code application and extracted selected quotes per theme, and then 
reviewed all coded excerpts and wrote a summary of results. We grouped themes at the levels of the social ecological model and examined the effects of ART use on respondents' health and wealth. As a final step, we extracted quotations to illustrate common themes or responses among ART clients. Each quotation was labeled with the client's sex and WHO HIV stage.

\section{Results}

\section{Sample Characteristics}

Table 1 describes the sample's demographic and health characteristics using survey and clinic data. The median age of participants was 32 years (range 18-56 years) and $50 \%$ of the participants were male, $68 \%$ were employed, and $55 \%$ had completed secondary education or more. More men in the sample had completed secondary education $(67 \%)$ relative to female respondents $(45 \%)$. The mean monthly income of participants was USD $\$ 43.50$. Men in the sample had a higher monthly mean income at $\$ 47$ compared to their female counterparts (\$40) even though more female respondents $(75 \%)$ reported being employed (largely driven by self-employment) than their male counterparts (61\%). Most participants (69\%) had a Stage 1 HIV classification (CD4 > 350 cells/ $\mu \mathrm{L}$ ) compared to $13 \%$ and $15 \%$ with Stage 2 and Stage 3 or 4 classifications (CD $4<350$ cells $/ \mu \mathrm{L}$ ), respectively. A little less than half of the sample $(45 \%)$ was virally suppressed (defined as having less than 200 copies $/ \mathrm{mL}$ ) based on the most recent viral load conducted at the clinic prior to the interview. 
Table 1

Sample Characteristics $(n=38)$

Variable

$N(\%)$

Sex

Female

$20(50 \%)$

Male

$20(50 \%)$

Employed

Not currently employed

$12(32 \%)$

Currently employed

$26(68 \%)$

Language

Luganda

$22(58 \%)$

English

$16(42 \%)$

Age

18-39 years

$26(65 \%)$

$40+$ years

$14(35 \%)$

Highest level of education completed ${ }^{a}$

None

$3(8 \%)$

Primary

$14(37 \%)$

Secondary

$16(42 \%)$

Vocational

$3(8 \%)$

University

$2(5 \%)$

Relationship

Not in relationship

$21(55 \%)$

In relationship

$17(45 \%)$

Notes: Data for sex and age obtained from clinic database, so $\mathrm{N}=40$, but others may not add up to same number due to missing survey data.

a Individuals in Uganda typically obtain vocational education after primary or secondary school education as post-primary or post-secondary training, but always prior to any university training.

${ }^{b}$ Income estimation is based on the sample after excluding 2 outliers due to their disproportionate likely due to data entry error. USD estimates calculated based on exchange rate of 1 USD $=3700$ Ugandan Shillings in January 2019 


\begin{tabular}{|lc|}
\hline Variable & $\mathbf{N}(\%)$ \\
\hline Mean monthly income ${ }^{\text {b }}$ & $\$ 43.50$ \\
\hline Virally suppressed at last clinic viral load $(<200$ copies $/ \mathrm{mL})$ & $18(45 \%)$ \\
\hline WHO HIV Infection Stage & $27(69 \%)$ \\
\hline Stage 1 (with CD4 $>350$ cells/ $\mu \mathrm{L})$ & $5(13 \%)$ \\
\hline Stage 2 (with CD4 < 350 cells/ $\mu \mathrm{L})$ & $6(15 \%)$ \\
\hline Stage 3 or 4 (with CD $4<200$ cells/ $\mu \mathrm{L})$ & \\
\hline $\begin{array}{l}\text { Notes: Data for sex and age obtained from clinic database, so N=40, but others may not add up to } \\
\text { same number due to missing survey data. }\end{array}$ & \\
\hline $\begin{array}{l}\text { a Individuals in Uganda typically obtain vocational education after primary or secondary school } \\
\text { education as post-primary or post-secondary training, but always prior to any university training. }\end{array}$ \\
\hline $\begin{array}{l}\text { b Income estimation is based on the sample after excluding } 2 \text { outliers due to their disproportionate } \\
\text { likely due to data entry error. USD estimates calculated based on exchange rate of } 1 \text { USD=3700 } \\
\text { Ugandan Shillings in January } 2019\end{array}$ \\
\hline
\end{tabular}

\section{Qualitative Interview Findings}

We identified several factors pertaining to the perceived effects of ART on health and wealth at individual, household, and structural levels that are described in further detail below. Table 2 summarizes these themes along with the relative frequency with which they were mentioned by participants in our sample. 
Table 2

Summary of themes describing multi-level effects of ART on Health and Wealth

\begin{tabular}{|c|c|c|c|}
\hline $\begin{array}{l}\text { Social } \\
\text { Ecological } \\
\text { Level }\end{array}$ & $\begin{array}{l}\text { ART } \\
\text { Benefits } \\
\text { ("the } \\
\text { effect of } \\
\text { ART on...") }\end{array}$ & Emerging themes & $\begin{array}{l}\text { Relative } \\
\text { frequency } \\
\text { b }\end{array}$ \\
\hline \multirow[t]{4}{*}{$\begin{array}{l}\text { Individual } \\
\text { (intrapersonal) }\end{array}$} & \multirow[t]{2}{*}{$\begin{array}{l}\text { Health } \\
\text { (lifestyle) }^{\text {a }}\end{array}$} & $\begin{array}{l}\text { - Increased physical improvements and lowered } \\
\text { susceptibility to illnesses }\end{array}$ & \multirow{2}{*}{$\star \star * \star$} \\
\hline & & $\begin{array}{l}\text { - Adoption of positive long-term habits (e.g., improved } \\
\text { nutrition and exercise) that help with physical and } \\
\text { mental health }\end{array}$ & \\
\hline & \multirow[t]{2}{*}{ Wealth } & $\begin{array}{l}\text { - Increased financial earnings and accompanying } \\
\text { savings from being able to work more regularly }\end{array}$ & \multirow{2}{*}{ 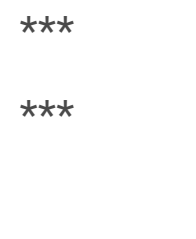 } \\
\hline & & $\begin{array}{l}\text { - Increased personal motivation to work harder and earn } \\
\text { more income }\end{array}$ & \\
\hline \multirow[t]{5}{*}{$\begin{array}{l}\text { Household } \\
\text { (interpersonal) }\end{array}$} & \multirow{3}{*}{$\begin{array}{l}\text { Health } \\
\text { (lifestyle) } \\
\text { a }\end{array}$} & $\begin{array}{l}\text { - Increased ability to do routine things (e.g. school, work, } \\
\text { raise children) and plan for future }\end{array}$ & \multirow{3}{*}{$\begin{array}{l}* * * \\
* \\
\star *\end{array}$} \\
\hline & & $\begin{array}{l}\text { - Reduced engagement in risky behaviors (e.g., } \\
\text { unprotected sex and substance use) }\end{array}$ & \\
\hline & & $\begin{array}{l}\text { - Improved social support and motivation from peers } \\
\text { and providers }\end{array}$ & \\
\hline & \multirow[t]{2}{*}{ Wealth } & $\begin{array}{l}\text { - Longer lifespan allows for more earning potential and } \\
\text { meeting family responsibilities }\end{array}$ & \multirow{2}{*}{$\star \star * *$} \\
\hline & & $\begin{array}{l}\text { - Improved social ties (leading to more friends and } \\
\text { business opportunities) }\end{array}$ & \\
\hline \multirow[t]{4}{*}{ Structural } & \multirow{3}{*}{$\begin{array}{l}\text { Health } \\
\text { (lifestyle) } \\
\text { a }\end{array}$} & - Disclosure to close friends and family & ** \\
\hline & & - Lowered stigma due to lack of illness & 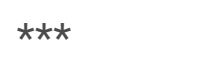 \\
\hline & & - Role of fatalism and the inevitability of death & ** \\
\hline & Wealth & $\begin{array}{l}\text { - Increased importance of forward-looking behavior and } \\
\text { civic responsibility (e.g., building businesses to help the } \\
\text { economy, helping other PLWH) }\end{array}$ & $\star \star \star \star ~$ \\
\hline
\end{tabular}

a The words "health" and "lifestyle" are interchangeable in the local context per the data collection team. As a result, when asked about the effects of ART on one's health, many respondents provided responses focused on their life goals (e.g. job, home, family etc.) rather than discussing immediate health-related impacts. For the purposes of this analysis, we have combined those themes.

${ }^{\mathrm{b}}$ Relative frequencies are denoted by: * discussed by $<25 \%$ of respondents (or $n<10$ ), ** discussed by $25-50 \%$ of respondents (or $n=10-20$ ), $* \star \star$ discussed by $>50 \%$ of respondents (or $n>20$ ) 


\section{Individual level factors}

Respondents described how they perceived of individual-level benefits to their health (via physical improvements to their health and well-being, being less susceptible to disease, and improved long-term personal habits) and wealth (increased motivation to work and earn more money).

\section{Health}

\subsection{Increased observable physical improvements and lowered susceptibility to illnesses}

Respondents were encouraged by the positive ramifications of taking medication, such as having more energy, gaining weight, and feeling stronger overall. One respondent cited feeling stronger after taking medicine, while another noted that without taking ART, she would feel unwell and weak and credited her ART medication to helping her gain energy and be healthy.

"My situation is now good... right now my body is okay, I am strong and well because when people look at me, they cannot believe that I even take medicine, even my wife." - Male, Stage 1

"I was badly off, used to be so tiny and had rashes, I even asked the doctor that will I ever get the medication and gain energy again. I was like 25 kilos but now am in 70s, I thank so much this hospital" Female, Stage 2

Respondents who tended to be at a higher disease stage also described being less susceptible to infection such as flu and other illnesses once they were adhering to their ART. One respondent described how she had not gotten sick from any illness ever since starting her ART and went as far as to say that without ART, she would not be alive.

"It has helped me a lot because if it's not for taking this medication then I wouldn't be alive. I no longer get diseases that disturb me like back then, it's now 10 years I have never gotten sick of malaria ever since I started taking the medication and I no longer get rashes. It has really helped a lot" -Female, Stage 2

Some respondents rationalized how ART can help them; they described factors such as a change in antibodies, lowered CD4 count, or higher viral load. A few of them also described how not taking ART would result in "waking the virus" and HIV would no longer be suppressed.

"It's possible because those who made this medicine first researched and found out that if a person uses this medicine and it suppresses the virus that came in the body, so if it sleeps and then antibodies continue to increase and do their work. That means a person can live a long life, because now the virus is suppressed so it's not doing any effect and every time it wakes up the antibodies have the power to fight" - Female, Stage 2 
"this one (who misses his dose of ART) might die without realizing it. He might just (have) small flu and we hear that he has died but he caused it himself because the doctor tells you have to take the medicine... If he (is) not using it well, the antibodies won't be moving well in other words the body is weak but this one that takes the body is not weak." - Female, Stage 1

\subsection{Adoption of positive long-term habits}

Few respondents also reported that taking ART regularly allowed them to adopt habits such as improved nutrition and exercise which would help them sustain their own physical and mental health in the longterm. One respondent cited the example of eating on time, improving personal hygiene, and participating in regular exercise, while another also cited how ART resulted in her going to more routine medical appointments. Others touted its benefits to their spiritual well-being (i.e., ART helped them focus on their religion) and mental health (i.e., ART helped them not worry about factors outside their control and gain more confidence in their actions).

"(when my body is HIV-free), I wake up and do my exercises well. Feeding well, I eat when it is time for me to eat. Also (I improve upon my) personal hygiene and (do) regular exercise" - Male, Stage 1

"(I am) eating well, (doing) exercise, (getting) routine checkups, not worrying. Even holding onto the Lord. "(I am) taking care of myself, I eat in time however small the food is. I also try not to overstress and over think a lot except a few things that may be hard to take in." - Female, Stage 1

"It has helped me to gain confidence and accept myself for who I am" - Female, Stage 1

\section{Wealth}

\subsection{Increased financial earnings and accompanying savings from being able to work more regularly}

Respondents described increases in their own financial earnings and accompanying savings from working more regularly and without interruptions. In the short term, one respondent for example described how she had more time to conduct personal matters and not come to the clinic repeatedly if she got sick, and in the long term, she could also work longer and earn more money.

"It has helped me because I am able to stay alive and work hard for my future." - Female, Stage 3

"Before I started coming here, I used to come to this place all the time, but when I started taking my medicine I can even spend three months without coming back here so I would get more time to attend to my personal issues. This helps me to increase my finances because I work at my own pace." - Female, Stage 1 


\subsection{Increased personal motivation to work harder and earn more income}

Respondents also described ramifications such as motivation and personal drive to work harder (and earn more money). One respondent made the direct connection between taking her medication regularly and working harder in her profession while another made the connection to living longer and having more time to work for her future.

"I think if you're taking your medication well, it encourages you to work hard. Like for my case, right now am doing a course in cosmetology and it keeps me healthy and good looking because if you don't take your medication, the effects of poor skin will show. And there is no way you will be working on someone and yet you yourself can't look as good as you're convincing them they will be. So I think it encourages us to work harder and it strengthens us, keeps us moving"- Female, Stage 1

"Of course, when you're taking medication, you will have to live longer and that means you will have more time to work for that future. The more you take your medicine well, your body is stronger, and you can work harder."- Female, Stage 1

One respondent described other forms of non-monetary "wealth" such as being able to survive for her family and provide for her daughter's education while another respondent described increased motivation to spread religious messages to others.

"(I) am not rich, but I work and get some money; but the little I get, I thank God. But even this wealth is there because if you got the virus when you had a child of five years and you educate her till when she completes...... isn't that wealth? Yet some time (ago) you would have died because you did not take well the medication (and) now you see that if I (am) certainly here and got checked when the kid was five years, but now she is educated and even gave birth, so that's wealth also....my wealth is my children- the fact (is I) am with them and I thank God for that because there is no wealth greater than a child." Female, Stage 1

"it will help me with more energy to spread the gospel to people. If I don't take drugs, I will be sick, and on Sundays it will be my day to go and I won't be able to make it."- Male, Stage 1

Another respondent drew this contrast more starkly by describing the futility of not taking one's medication, comparing the situation to not having any wealth in the short-term at all.

"The one who doesn't take the medication has no wealth at all and he has no purpose on earth... The one who doesn't take the medication might be dying soon." -Female, Stage 1

\section{Household level factors}


Respondents made the connection between ART-related benefits to health and wealth at the household level by describing how ART helped them continue to do routine things and plan for their futures, while also deriving benefits from social support and reduced engagement in risky behavior in the process.

\section{Health}

\subsection{Increased ability to do routine things (e.g. school, work, raise children) and plan for future}

Individuals said that after taking ART regularly, they could conduct normal activities such as going to work or school, maintaining a job, and even raising a family.

"Basically at school, mentally I am very fit. Before my medication, I used to be a person that, I don't know, maybe fear of my condition but now I am okay" -Female, Stage 1

The ability to plan for families (and have children who are not HIV positive) was a recurring theme, especially among female respondents.

"It has helped me because I am now happy, because I did not expect to give birth to a child who is negative, but he is now negative. It gives me encouragement." - Female, Stage 1

"This boyfriend I have first of all he wants kids, and there is some counselor who told that if you're on medication you might not infect your boyfriend who is not infected, so in my future I might get a person who is not infected and I don't infect him and even our kids might be normal. And even the future of a job is good because you be taking your medication, when your health too, so you can't be fired at work." Female, Stage Unknown

\subsection{Reduced unprotected sex and substance use}

Male respondents also mentioned how taking ART mitigated the negative influence of family and friends. Respondents reported reduced engagement in risky behavior such as unprotected sex and substance abuse. Interestingly, none of the female respondents cited these factors.

"What might stop me from living long is maybe going back to something like adultery; I used to take alcohol but its good when you are taking medicine. I also used to take cigarettes and I left it when they told me it wasn't good for the medication, they told me too to eat well and also (be more mindful of) God because I allowed Him to enter my life. I thank God that He has keep live for long."- Male, Stage 3

"You do not have to go out with girls without protection because even if you take medicine you can still get infected with other diseases that can kill you. Sometimes you take medicine and smoke and (use) alcohol, it affects your life. There is also a bad reaction when you take the medication and take alcohol, it is a bad feeling" - Male, Stage 1 
One respondent suggested that reduced engagement in risky behavior translated to savings because he avoided risky activities that he would have otherwise engaged in had he not been taking his medication.

"It helps me because a lot of boys I live with as for them, he can spend his money and goes for women but as for me I do not usually do that because I am keeping my money because I know my life depends on the medication because the medication does not interact with alcohol." - Male, Stage 2

\subsection{Improved social support and motivation from peers and providers}

Respondents also cited additional benefits from ART-one respondent described the positive social support she received from her friends while another cited the support from colleagues whom he met at the clinic who encouraged him to continue taking his medication.

"Even being with people if I see that the thoughts are coming, I go to them instead of locking myself inside in the house. There is a salon. I can sit there for a while and there are tenants whom I chat with and laugh. I also have a tendency of eating well with people around but if they are not around then it becomes difficult, maybe this thing of my eyes which tend to be painful, and I can't read the bible and that treats me bad. Because I had novels at home, but now I can't read them." - Female, Stage 2

"I see (similar situation) from colleagues who come here so I tell myself that I am not the only one infected. Some of my friends encourage me to take the medication because they know that this is my life." - Male, Stage 2

\section{Wealth}

\subsection{Longer lifespan allows for more earning potential and meeting family responsibilities}

Respondents suggested that in the future, their wealth and that of their household would likely be higher as they wouldn't be sick and could save more money and be financially independent and support their families.

"Most times I pray to be my own boss- that's what am fighting for: to get my own business basically I see a bright future because of the long life I will be having (due to ART). My financial status might increase in the future." - Male, Stage 3

Female respondents especially highlighted being able to save and carry out their familial responsibilities such as being able to do more for children e.g., paying their school fees, building a home etc. 
"... I take well my medication I can be alive and work for my kids....(and) taking my medication helps not to get sicknesses, and (then) I can (be able to) wake up early and look for something to eat for my kids.. What I know is if (I am) able to work and earn (due to taking ART), I can take care of my kids and also, I can earn since the kids don't get sick hence, I can have a little to save." - Female, Stage 1

"So far it is very good that these medicines are free, therefore we can save some money and currently I and my husband have started building a house of our own and my first-born child is in senior Five. She's 17 years." - Female, Stage 1

"It has helped to get energy to be able to work for my kids, being able to prepare for my kids; before I started taking the medication, I used to be weak, and I couldn't do anything. But ever since I started taking the medication I can work and even be able to pay school fees." - Female, Stage 1

\subsection{Improved social ties (leading to more friends and business opportunities)}

Some also suggested the benefits of improved social ties because of taking ART regularly-respondents extended this to widening their friends circle and getting lucrative business opportunities.

"It (taking ART regularly) has helped me to get a lot of things, seeing new things, living up to my youth age, getting new friends like that" - Male, Stage 3

"If you're sick like coughing or you're down bedridden, nobody will make business with you. So you take the medicine to stay strong, because nobody will make money if they are bedridden" - Male, Stage 1

\section{Structural factors}

Respondents described structural factors stemming from the local political, institutional, and cultural context that influenced how they perceived ART benefits; these included comfort around disclosure, lowered stigma, the idea of fatalism, and general forward-looking behavior such as having a sense of civic responsibility.

\section{Health}

\subsection{Motivates or enables disclosure to close friends and family}

Some reported that taking ART and then getting better is a key driver in being able to disclose HIV status to loved ones. One respondent indicated that taking ART regularly and the promise of subsequent 
"healing" motivated him to disclose his status to his partner. Another respondent described how taking his medication helped with the stigma he faced prior to taking his medication.

"I have a girlfriend, but she doesn't even know that am infected. I have a time when I want to tell her, and I have never touched her like having sex but inside l ask myself "what if she gets to know", so that makes me take medication hurriedly so that they next time they check me I might be healed. My dream is to heal." - Male, Stage 1

\subsection{Improved hope and greater aspirations for future and lowered stigma}

Other respondents cited additional effects of ART such as renewed hope and aspirations for the future, especially since lack of illness lowered social stigma associated with HIV and being on ART made them realize they could live longer.

"....even their social life will be easy in (a) community because the community will not stigmatize them as it will be a warm society as they live socially like any other person as they have accepted their status and lived on with it." - Female, Stage 1

"At first, I could not believe (when I was told about my status) because they told me when I was 8 years that I was positive, and I thought I was going to die like my mother. I am now 19 years; around 11 years have passed by. I did not know that I would reach this far, but if I have reached here, then I know I can go further ahead. I thought I was the only one but I met a man and he told me all his kids were like me and he started taking the medication when he was 10 years old, but he is now around 40 years. That gave me courage and strength and I told myself I am not going to die, I have a life ahead of me." - Male, Stage 1

Another respondent described how taking his medication helped with the social stigma he faced prior to taking his medication.

"Let me say like that time when they told me I had to take the medication, I saw that people were going to start laughing at me and I even wanted to kill myself but then they told me to take the medication hence I will be better than the other normal people. So they told me that don't kill yourself because (you're) like a normal person now and no one suspect that you're infected or not." - Male, Stage 2

\subsection{Greater fatalism (especially in thinking about inevitability of death)}

Respondents also appeared to describe how being on ART minimized (and not enhanced) their sense or fear of death-some of them attributed this to fatalism and the inevitability of death, tying it closely to their religious beliefs. 
"In my own thinking they say we came from God and it's where we shall go back but for me, I think even AIDS won't kill me, I will die of something else. There are God's plans because you can't say that I won't die, if it's about AIDS me I think I live long but I die of something else."-Female, Stage 2

"I think God is the one that makes for us a calendar and everyone has their own calendar." - Female, Stage 1

\section{Wealth}

\subsection{Increased importance of forward-looking behavior and civic responsibility}

While most respondents did not allude to broader societal factors that described the effect of ART on wealth, few of them discussed how taking ART helped them think about the future and their civic role such as building a business in Uganda and contributing to the welfare of others, especially other PLWH.

"(After taking ART), first, my life will add on (and enrich) as a result. I will get more strength so that I can work, because for me, my dream is to become a businessman and to help my country Uganda" - Male, Stage 3

"When I take my medication, I hope to get a job in the future, to make my own company producing my own things, help infected people like me. So for me to take my medication I know that in the future I have a dream. That means I have to take the medication to fulfill my dream. " - Male, Stage 1

\section{Discussion}

We conducted a qualitative study among clinic enrolled Ugandan PLWH and examined the kinds of benefits they experienced in terms of their health and wealth. Our findings outline the context PLWH face when thinking about the broad benefits of ART to their lives, especially their attitudes and expectations of future outcomes resulting from ART-this topic remains largely unexplored in the qualitative literature. Such factors can provide a promising lens to better understand the benefits of ART that go beyond the short-term health related benefits. In our study, such benefits included those at the individual, household, and structural levels, and largely focused on their ability to live longer and be physically and mentally healthy, while also fulfilling responsibilities pertaining to themselves (in terms of positive long-term habits and motivation to work harder), others (such as improved relations with family and friends), and society (in terms of improved civic responsibility). Our study findings can be useful as testimonials for promoting ART expansion and investment in ART, as well as for future programming meant to target these areas as they can help understand how or why ART clients perceive certain benefits, especially those that are accrued in the long-term.

At the individual level, respondents described the health-related benefits of ART in terms of physical health improvements and lack of illness, as well as adoption of positive long-term habits over their longer 
lifespan. Respondents felt they had more control of their health and well-being because of adhering to ART. Wealth-related benefits included increased financial earnings and increased personal motivation to work harder. Prior research has quantitatively examined how increases in life expectancy stemming from ART can encourage forward-looking behavior because individuals are aware of their lowered mortality risk and subsequently make different life decisions $[12,18]$. These studies have sought to examine how PLWH respond to taking ART and change their patterns of risk-taking, information-seeking, and monetary investments in children (especially in education and clothing) $[16,18,29]$. The qualitative findings from our study substantiate and contextualize some of these changes reported elsewhere; respondents on ART believe they will have a longer life with HIV and they can see direct benefits to themselves in terms of both their health and personal wealth.

At the household level, respondents highlighted benefits of ART on health and wealth, such as increased ability to do routine things, plan for their future and have a higher income potential. Female respondents especially described how ART helped them to better plan for their future and raise children who are not HIV positive, while also earning money to meet the needs of their families. This finding corroborates evidence from other studies describing that adherence to ART changes the context of childbearing for PLWH, specifically since having children indicates that PLWH are leading a healthy adult life [30]. A metaanalysis found that the prevalence for fertility desires was $42 \%$ among PLWH, and this was higher among male PLWH [31]. Our qualitative findings in this clinic-enrolled sample of PLWH show that females were more likely to describe these ART-related benefits. This could indicate that counseling and reproductive health care be provided to female PLWH who generally would feel a greater sense of responsibility to their families. Male respondents on the other hand described the importance of ART in helping to reduce risky behavior such as unprotected sex and substance abuse. Such behaviors are well established risk factors for poor HIV care outcomes, especially in terms of facilitating testing uptake, engagement and retention in care, and ART use and adherence [32]. Evidence from Kenya and Uganda has shown that alcohol use especially among men was associated with decreased ART use, mostly due to poor engagement and retention in care [33]. Our qualitative findings among male respondents suggest that future ART support interventions may benefit from being more tailored to drinkers or even those with low or medium level alcohol use. As care models of ART delivery branch out of the clinic, adherence support interventions should take advantage of such targeted messaging to incentivize PLWH who could possibly benefit from changes to their benefits and enhance the benefits they derive from ART.

At the structural level, many respondents described the link of ART with comfort in HIV status disclosure, lowered stigma, and increased civic responsibility. Our qualitative findings are in line with related evidence which describes how ART can reduce internalized stigma in Uganda and even hasten disclosure due to improved coping mechanisms and social support [34]. All respondents highlighted the link with employment and ability to increase their earnings if they continued taking their ART. Some of these findings are consistent with studies highlighting the important role of employment in ART adherence. This literature describes the supportive role of employment among PLWH because it is associated with improved adherence; these studies normally describe the factors that determine adherence since financial constraints are a key barrier to ART adherence. A systematic review of ART adherence and employment 
status described how employed PLWH were $27 \%$ more likely to adhere to ART than their unemployed counterparts $[35,36]$. Our findings corroborate other studies also reporting that benefits described by our study respondents (e.g. improved wealth, employment etc.) are associated with movement along the HIV care continuum $[37,38]$. Respondents who cite these benefits will be more likely to engage in continued care and improved adherence.

Our study was subject to several limitations; while there were some observable differences in themes across male and female respondents, we were not able to assess if benefits varied based on access, availability, or quality of education, jobs, or other factors related to the benefits described by respondents. This difference may be possible to assess with a larger qualitative sample. Our findings may also differ with a study sample that was not enrolled in a study seeking to improve adherence among low adherersthese individuals may already believe that ART improves health. The ordering of the questions (starting with health, describing effects on life expectancy, and then finally wealth) may have followed a natural order, but perhaps responses would be slightly different if the order were switched. Each participant was also interviewed only once, and had they been interviewed at the end of the 2-year parent study, we could assess if their perspectives had changed, and collected data on whether they experienced first-hand any of the benefits they described. While not exactly a limitation, the study findings point to the discrepancy between participants perceiving the benefits of ART to their health and wealth, yet not adhering to their medication (which is why they are enrolled in a treatment adherence RCT). This could be due to a desirability bias where they may not internalize the messages about ART, or they may be subject to shortterm structural and behavioral barriers (such as behavioral biases) that prevent them from fully realizing the benefits they mentioned in the qualitative findings.

Strengths of this study include the fact that we included individuals on long-term ART with recent adherence problems in a clinical setting and investigated the benefits of ART in two distinct domains within their lives: health and wealth. This subject has previously not been studied extensively in literature using qualitative methods and can help understand how PLWH Perceive these benefits

\section{Conclusions}

When recounting the contributions of ART in their lives, PLWH do not simply consider the short-term health benefits, but also the longer-term implications on other domains. This is evident from the findings of this qualitative study. Our study findings can be used to better promote the expansion of ART and help donors understand the broader benefits of ART. We provide contextualized evidence on broader social and economic evidence pertaining to ART. As described by participants, improvements in health via ART can affect future health and income by making individuals more productive (e.g., being able to attend school and get the requisite skills, attain better social networks etc.). Interventions can be designed with these benefits in mind for individuals who don't specifically recognize such benefits (e.g., treatment initiators), and can specifically use short and long-term individual-level factors to drive improvements in uptake (e.g., by encouraging healthier habits, or helping to increase household income). 
Findings at the household and structural levels can be useful to clinic staff such as providers or counselors who are encouraging PLWH to sustain ART use. Evidence from other parts of SSA such as in South Africa suggests the need to incorporate this kind of evidence for treatment adherence-in that context, individuals discontinued ART because they were uncertain about its value and overall benefit in their lives [39]. Having benefits - such as counseling for their future or resources on ways to get involved helping their communities - directly integrated into the design of interventions can be useful especially in a context when PLWH face so many competing interests to increase medication adherence. These benefits can ultimately help providers and policymakers improve ART-related outcomes. Further research is warranted to determine how these benefits differ across groups of PLWH, especially those with varying levels of access to ART, retention, or linkage to care in HIV care programs, or other sociodemographic factors. Additional research can also examine whether these ART benefits can result in changes in behavior such as increased human capital investments.

\section{Declarations}

\section{Ethics approval and consent to participate}

We obtained ethics approval from the RAND Corporation's Human Subjects Protection Committee (\#2016-0956), the Mildmay Uganda Research Ethics Committee Institutional Review Board (\#020132018), and the Uganda National Council for Science and Technology (\#2394). Written informed consent to participate in the study was obtained from all participants prior to the start of data collection once the survey objectives and procedures were explained at study enrollment. All methods were performed in accordance with the relevant guidelines and regulations set forth by the various ethics approval agencies.

\section{Consent for publication}

Not applicable

\section{Availability of data and materials}

Datasets generated and/or analyzed during the current study are not publicly available due the restrictions statement in our study consent forms.

\section{Competing interests}

The authors declare that they have no competing interests.

\section{Funding}


The parent study was funded through resources provided by the National Institute of Mental Health (Grant: R01MH110350, PI: Linnemayr). Additional support for this study was provided by the Pardee Dissertation Award for Global Human Progress between 2018-2021 (Pardee RAND Graduate School). The content of this paper is solely the responsibility of the authors and does not necessarily represent the official views of the NIH.

\section{Author Contributions}

US led the analysis and interpretation of the interview data and led the writing of the manuscript along with mentorship and guidance from SM. PW and LL supported study implementation and data collection, and BM provided field-based supervision and overall study monitoring in Kampala. ZW provide guidance on analysis. SL conceptualized and implemented the underlying parent study and supported the writing of the manuscript. All authors read and approved the final manuscript.

\section{Acknowledgements}

The authors wish to thank the Mildmay clinic and the U.S. and Ugandan RAND research staff. We are particularly grateful to our excellent study team members: Stewart Walukaga, Pius Kimuli, and Philip Aroda. We also extend our gratitude to the ART clients who generously provided their time and described their experiences with ART that ultimately made this study possible.

\section{References}

1. UNAIDS [Internet]. Global HIV \& AIDS statistics - 2020 factsheet. 2020 [cited 2021 Sep 9]. Available from: https://www.unaids.org/en/resources/fact-sheet

2. Samji H, Cescon A, Hogg RS, Modur SP, Althoff KN, Buchacz K, et al. Closing the gap: increases in life expectancy among treated HIV-positive individuals in the United States and Canada. PLoS One. 2013;8(12):e81355.

3. Farnham PG, Holtgrave DR, Gopalappa C, Hutchinson AB, Sansom SL. Lifetime costs and qualityadjusted life years saved from HIV prevention in the test and treat era. Vol. 64, Journal of acquired immune deficiency syndromes (1999). United States; 2013. p. e15-8.

4. Cohen MS, Chen YQ, McCauley M, Gamble T, Hosseinipour MC, Kumarasamy N, et al. Prevention of HIV-1 infection with early antiretroviral therapy. N Engl J Med. 2011 Aug;365(6):493-505.

5. Gill CJ, Hamer DH, Simon JL, Thea DM, Sabin LL. No room for complacency about adherence to antiretroviral therapy in sub-Saharan Africa. AIDS. 2005 Aug;19(12):1243-9.

6. Gallant JE. Strategies for Long-term Success in the Treatment of HIV Infection. JAMA [Internet]. 2000 Mar 8;283(10):1329-34. Available from: https://doi.org/10.1001/jama.283.10.1329

7. Eshun-Wilson I, Rohwer A, Hendricks L, Oliver S, Garner P. Being HIV positive and staying on antiretroviral therapy in Africa: A qualitative systematic review and theoretical model. PLoS One. 
2019;14(1):1-30.

8. Shubber Z, Mills EJ, Nachega JB, Vreeman R, Freitas M, Bock P, et al. Patient-Reported Barriers to Adherence to Antiretroviral Therapy: A Systematic Review and Meta-Analysis. PLoS Med. 2016 Nov;13(11):e1002183.

9. Yu Y, Luo D, Chen X, Huang Z, Wang M, Xiao S. Medication adherence to antiretroviral therapy among newly treated people living with HIV. BMC Public Health. 2018 Jul;18(1):825.

10. MacCarthy S, Saya U, Samba C, Birungi J, Okoboi S, Linnemayr S. "how am i going to live?": Exploring barriers to ART adherence among adolescents and young adults living with HIV in Uganda. BMC Public Health. 2018;18(1):1-11.

11. Ahmed S, Autrey J, Katz IT, Fox MP, Rosen S, Onoya D, et al. Why do people living with HIV not initiate treatment? A systematic review of qualitative evidence from low- and middle-income countries. Soc Sci Med [Internet]. 2018;213:72-84. Available from: https://www.sciencedirect.com/science/article/pii/S0277953618302910

12. Fortson JG. Mortality Risk and Human Capital Investment: The Impact of HIV/AIDS in Sub-Saharan Africa. Rev Econ Stat [Internet]. 2011;93(1):1-15. Available from: https://doi.org/10.1162/REST_a_00067

13. Jayachandran S, Lleras-Muney A. Life Expectancy and Human Capital Investments: Evidence from Maternal Mortality Declines. Q J Econ [Internet]. 2009;124(1):349-97. Available from: https://doi.org/10.1162/qjec.2009.124.1.349

14. Bor J, Herbst AJ, Newell M-L, Bärnighausen T. Increases in Adult Life Expectancy in Rural South Africa: Valuing the Scale-Up of HIV Treatment. Science (80-) [Internet]. 2013;339(6122):961-5. Available from: https://science.sciencemag.org/content/339/6122/961

15. Gong E. HIV Testing and Risky Sexual Behaviour. Econ J [Internet]. 2015;125(582):32-60. Available from: https://onlinelibrary.wiley.com/doi/abs/10.1111/ecoj.12125

16. Friedman WH. Antiretroviral drug access and behavior change. J Dev Econ [Internet]. 2018 Nov 1 [cited 2019 Jun 26];135:392-411. Available from:

https://www.sciencedirect.com/science/article/pii/S0304387818304516\#bib4

17. Baranov V, Bennett D, Kohler H-P. The Indirect Impact of Antiretroviral Therapy: HIV Risk, Mental Health, and Labor. 2014;44:195-211.

18. Baranov V, Kohler H-P. The Impact of AIDS Treatment on Savings and Human Capital Investment in Malawi. Am Econ J Appl Econ [Internet]. 2018 Jan;10(1):266-306. Available from: http://www.aeaweb.org/articles?id=10.1257/app.20150369

19. Bor J. Survival Expectations and Human Capital Investment: Experimental Evidence from Rural South Africa. PAA Abstr. 2019;

20. Tong A, Sainsbury P, Craig J. Consolidated criteria for reporting qualitative research (COREQ): A 32item checklist for interviews and focus groups. Int J Qual Heal Care. 2007;19(6):349-57.

21. Linnemayr S, Stecher C, Saya U, MacCarthy S, Wagner Z, Jennings L, et al. Behavioral Economics Incentives to Support HIV Treatment Adherence (BEST): Protocol for a randomized controlled trial in 
Uganda. Trials. 2020;21(1):9.

22. Godin G, Kok G. The Theory of Planned Behavior: A Review of its Applications to Health-Related Behaviors. Am J Heal Promot [Internet]. 1996;11(2):87-98. Available from: https://doi.org/10.4278/0890-1171-11.2.87

23. Munro S, Lewin S, Swart T, Volmink J. A review of health behaviour theories: how useful are these for developing interventions to promote long-term medication adherence for TB and HIV/AIDS? BMC Public Health [Internet]. 2007;7(1):104. Available from: https://doi.org/10.1186/1471-2458-7-104

24. McLeroy KR, Bibeau D, Steckler A, Glanz K. An ecological perspective on health promotion programs. Health Educ Q. 1988;15(4):351-77.

25. Ahmed C V, Jolly P, Padilla L, Malinga M, Harris C, Mthethwa N, et al. A qualitative analysis of the barriers to antiretroviral therapy initiation among children 2 to 18 months of age in Swaziland. African J AIDS Res [Internet]. 2017;16(4):321-8. Available from: https://doi.org/10.2989/16085906.2017.1380677

26. Kagee A, Remien RH, Berkman A, Hoffman S, Campos L, Swartz L. Structural barriers to ART adherence in Southern Africa: Challenges and potential ways forward. Glob Public Health. 2011;6(1):83-97.

27. Thomas DR. A General Inductive Approach for Analyzing Qualitative Evaluation Data. Am J Eval. 2006;27(2):237-46.

28. Hsieh H-F, Shannon SE. Three Approaches to Qualitative Content Analysis. Qual Health Res [Internet]. 2005 Nov 1;15(9):1277-88. Available from: https://doi.org/10.1177/1049732305276687

29. de Walque D, Kazianga H, Over M. Antiretroviral Therapy Perceived Efficacy and Risky Sexual Behaviors: Evidence from Mozambique. Econ Dev Cult Change [Internet]. 2012;61(1):97-126. Available from: https://doi.org/10.1086/666951

30. Wekesa E, Coast E. Fertility desires among men and women living with HIV/AIDS in Nairobi slums: a mixed methods study. PLoS One. 2014;9(8):e106292.

31. Yan X, Du J, Ji G. Prevalence and factors associated with fertility desire among people living with HIV: A systematic review and meta-analysis. PLoS One. 2021;16(3):e0248872.

32. Monroe AK, Lau B, Mugavero MJ, Mathews WC, Mayer KH, Napravnik S, et al. Heavy Alcohol Use Is Associated With Worse Retention in HIV Care. J Acquir Immune Defic Syndr. 2016 Dec;73(4):419-25.

33. Puryear SB, Balzer LB, Ayieko J, Kwarisiima D, Hahn JA, Charlebois ED, et al. Associations between alcohol use and HIV care cascade outcomes among adults undergoing population-based HIV testing in East Africa. AIDS. 2020 Mar;34(3):405-13.

34. Tsai AC, Bangsberg DR, Bwana M, Haberer JE, Frongillo EA, Muzoora C, et al. How does antiretroviral treatment attenuate the stigma of HIV? Evidence from a cohort study in rural Uganda. AIDS Behav. 2013 Oct;17(8):2725-31.

35. Nachega JB, Uthman OA, Peltzer K, Richardson LA, Mills EJ, Amekudzi K, et al. Association between antiretroviral therapy adherence and employment status: systematic review and meta-analysis. Bull World Health Organ. 2015 Jan;93(1):29-41.

Page 24/25 
36. Mills EJ, Nachega JB, Bangsberg DR, Singh S, Rachlis B, Wu P, et al. Adherence to HAART: A systematic review of developed and developing nation patient-reported barriers and facilitators. PLoS Med. 2006;3(11):2039-64.

37. Conyers LM, Richardson LA, Datti PA, Koch LC, Misrok M. A Critical Review of Health, Social, and Prevention Outcomes Associated With Employment for People Living With HIV. AIDS Educ Prev Off Publ Int Soc AIDS Educ. 2017 Oct;29(5):475-90.

38. Maulsby $\mathrm{CH}$, Ratnayake A, Hesson D, Mugavero MJ, Latkin CA. A Scoping Review of Employment and HIV. AIDS Behav. 2020 Oct;24(10):2942-55.

39. Dahab M, Kielmann K, Charalambous S, Karstaedt AS, Hamilton R, La Grange L, et al. Contrasting reasons for discontinuation of antiretroviral therapy in workplace and public-sector HIV programs in South Africa. AIDS Patient Care STDS. 2011 Jan;25(1):53-9.

\section{Supplementary Files}

This is a list of supplementary files associated with this preprint. Click to download.

- AppendixSayaBMCPH.docx 